\title{
HUMAN T-LYMPHOTROPIC VIRUS (HTLV) TYPE I IN VIVO INTEGRATION IN ORAL KERATINOCYTES
}

\section{Martha C. Domínguez, Norma Enith González, Adalberto Sánchez, Felipe García Vallejo*}

Laboratory of Molecular Biology and Pathogenesis. Department of Physiological Sciences. Faculty of Health. University of Valle, Cali, Colombia.

\begin{abstract}
Although the infection of HTLV-1 to cell components of the mouth have been previously reported, there was not until this report, a detailed study to show the characteristics of such infection. From 14 Tropical Spastic Paraparesis/ HTLV-1-Associated Myelopathy (HAM/TSP) patients and 11 asymptomatic carrier individuals (AC) coming from HTLV-1 endemic areas of southwest Pacific of Colombia, infected oral mucosa cells were primary cultured during five days. These cell cultures were immunophenotyped by dual color fluorescence cell assortment using different lymphocyte CD markers and also were immunohistochemically processed using a polyclonal anti-keratin antibody. Five days old primary cultures were characterized as oral keratinocytes, whose phenotype was CD3- /CD4-/CD8-/CD19-/CD14-/CD45/A575-keratin+. From DNA extracted of primary cultures LTR, pol, env and tax HTLV-1 proviral DNA regions were differentially amplified by PCR showing proviral integration. Using poly A+ RNA obtained of these primary cultures, we amplify by RT-PCR cDNA of tax and pol in $57.14 \%$ (8/14) HAM/TSP patients and 27.28\% (3/11) AC. Tax and pol poly A+ RNA were expressed only in those sIgA positive subjects. Our results showed that proviral integration and viral gene expression in oral keratinocytes are associated with a HTLV-1 specific local mucosal immune response only in those HTLV-1 infected individuals with detectable levels of sIgA in their oral fluids. Altogether the results gave strong evidence that oral mucosa infection would be parte of the systemic spreading of HTLV-1 infection.
\end{abstract}

Key words: Oral keratinocytes. Oral mucosa. Human T-Lymphotropic virus type 1. Proviral integration. sIgA.

\section{INTRODUCTION}

Human T-Lymphotropic virus - HTLV-1 is a human retrovirus initially associated with $\mathrm{T}$-cell malignancies (27). HTLV-1 is a persistent virus, infecting 10 to 20 million people worldwide (28). Although, most of infected individuals remain as asymptomatic carriers, 1 to $2 \%$ develops the Tropical Spastic Paraparesis/HTLV-1-associated myelopathy (HAM/TSP) (24), and further 2 to $3 \%$ develop an aggressive Tcell leukemia/lymphoma (ATLL) (17). In addition to ATLL and HAM/TSP, HTLV-1 has been associated with a range of chronic or subacute inflammatory conditions in different

*Corresponding Author. Mailing address: Head of the Laboratory of Molecular Biology and Pathogenesis. Professor at the Department of Physiological Sciences. School of Basic Sciences. Faculty of Health. University of Valle. Cali. Colombia. P.O Box 25360.; Tel.: (572)518 5601. Fax: (572)518 5617.; E-mail: labiomol@gmail.com 
tissues. These associations are weaker than those with ATL and HAM/TSP, and it is not yet agreed that HTLV-1 is the likely cause in each condition (19).

Over the last 25 years the geographical distribution of the HTLV-1 has been identified. The seroprevalence rates differ, according to geographic area, the socio-demographic composition of the population studied and individual risk behaviors. The areas of the world with the highest prevalence rates for HTLV-1 include southwestern Japan, several subSaharan African countries, Central and South America, and localized areas of Iran and Melanesia. In the Americas, higher prevalence rates are found in some countries in the Caribbean, such as Jamaica and Trinidad and Tobago. Somewhat lower seroprevalence rates are found in several countries in South America, including Brazil and Colombia $(28,37)$.

HTLV-1 is transmitted in three ways: (i) from mother to child during prolonged breastfeeding (12, 36); (ii) between sexual partners, mainly from man to woman (10); and (iii) through blood transfusion with HTLV-1nfected cells (22). In areas where the virus is highly endemic, mother-to-child transmission is sometimes the predominant route. Previous reports have suggested as a possible mode of virus transmission the oral fluids of infected individuals (38); recent evidence have documented transmission of HTLV-1 to rats by inoculation with human fluids or cells from infected subjects (32)

Previously we reported that secretory IgA antibody class specific to HTLV-1 proteins in oral fluids of seropositive individuals was correlated with the presence of free genomic RNA in oral fluids of HAM/TSP patients (33). Other studies have shown the detection of viral genomes in salivary secretions and provirus in DNA of salivary lymphocytes (1) and epithelial mouthwash cells (18).

In the present study we showed how several HTLV-1 proviral genomic regions were amplified by PCR from DNA extracted of oral cultured keratinocytes from HTLV-1 infected individuals. Moreover the detection of tax and pol viral poly A+ RNA was correlated with the detection of specific anti-taxsIgA in oral fluids of HAM/TSP patients. Our results gave strong evidences to propose that HTLV-1 in oral epithelium would be a part of the systemic spreading of virus in the host.

\section{MATERIALS AND METHODS}

\section{Patients and samples}

Twenty-five HTLV-1 seropositive individuals from different villages of southwest pacific of Colombia were included in this study. Fourteen were well characterized as HAM/TSP patients according with standard criteria (23) (average age 54.8 \pm 11.5$) ; 11$ asymptomatic carriers (AC) (average age $45.1 \pm 12.8$ ) were also included into the study. As negative controls we included 20 negative HTLV-1/2 negative controls once the ELISA and WB used gave results for both viruses. The study was approved by the Research Ethics Committee of the Health Sciences Faculty of the Universidad del Valle, Cali, Colombia according to the Declaration of Helsinki. All persons enrolled in it were informed about their objectives and consent to donate blood and oral samples only for research purposes. Oral fluid (OF) samples were taken using the FDA approved commercial device Orasure $^{\mathrm{TM}}$ (Epitope Inc., Beaverton, OR), following the instructions of the manufacturers. Patient's blood samples were taken and plasma and lymphocytes were recovered with Hystopaque-1077 (SIGMA) gradients according with the general protocols. Lymphocytes were cryopreserved in DMSO-RPMI1640 $(1: 1 \mathrm{v} / \mathrm{v})$ storage medium at $-156^{\circ} \mathrm{C}$ until their use.

\section{HTLV-1 ELISA and Western blot}

ELISA Murex HTLV I + II (Murex Biotech Limited. Dartford. UK) diagnostic kit was used for virus screening. Dilutions of 1:40 for plasma and 1:2 for OF were used to test every paired sample. Microplates were washed twice and incubated with goat IgG-antiIgG-, IgM- (Sigma Chemical Co, St. Louis, MO) and sIgA (Chapel, Organon Teknika, West Chester, PA) peroxidase labeled conjugate diluted 1:15,000, 1:1000 and 1:2000 respectively. The results were expressed as an OD ratio (OD sample/OD cutoff) and normalized for protein content in OF. Determination of protein concentration in oral 
samples was performed with the Bradford colorimetric method (3). An OD ratio $\geq 1.1$ was a criterion of seropositivity.

The HTLV-1 confirmation in plasma and OF was performed by western blot using HTLV blot 2.4 assay kit $\left(\right.$ Genelabs ${ }^{\circledR}$ Diagnostics Pte Ltd. Singapore Science Park. Singapore). OF samples were also analyzed by western blot with a 50-kDa HTLV-1-tax recombinant protein (21).

\section{Primary cultures of oral epithelial cells}

Using a cotton swabs oral epithelial cells were obtained, they were harvest in transporting minimal essential medium (MEM), L-Glutamine $200 \mathrm{mM}$ supplemented with antibiotics; in all cases the viability of cells was monitored by staining with blue trypan. After that, they were incubated in microplates at $37^{\circ} \mathrm{C}$ in $5 \% \mathrm{CO}_{2}$ atmosphere in MEM, $15 \%$ bovine fetal serum, penicillin $(49 \mu \mathrm{g} / \mathrm{ml})$, amphotericin $(4 \mu \mathrm{g} / \mathrm{ml})$, and L-Glutamine 200mM; the culture medium were changed every two days. Cell growing was daily monitored by staining with blue trypan and cell counting was performed with an inverted light microscope. After 5 days (monolayers with more than $60 \%$ of confluence), the cultures were submitted to immune staining with a polyclonal anti-keratin antiserum A-575 (Daco, Carpinteria, CA) using the Vectastain Elite ABC kit (Vector, Burlingame. CA). The cultures did begin with $5 \times 10^{3}$ cells $/ \mathrm{ml}$ and after five days reached they an average cell density of $1.7 \times 10^{6}$ cells $/ \mathrm{ml}$.

\section{Two color flow citometry}

Oral epithelium primary cultures were analyzed by two color fluorescence in a FACSTAR PLUS cell sorter (BecktonDickinson, Mountain View, CA) for $\mathrm{T}, \mathrm{B}$, macrophage, monocyte and Langerhan cell surface marker expression with monoclonal antibodies to CD3, CD4, CD8, CD19 and CD45 (Becton-Dickinson, Mountain View, CA). The FACS analyses were carried out 24 hours after seeding and also in cultures of five days.

\section{DNA extraction and PCR protocols}

DNA from primary cultures of oral epithelium cell was obtained according with Ramirez-Solis et al, 1992 protocol (31). Purity of DNA was calculated using the values of O.D $260 \mathrm{~nm} / \mathrm{O}_{280 \mathrm{~nm}}$ ratio; a DNA preparation with O.D ratio $\geq$ 1.8 was considered pure and suitable for PCR. Each PCR reaction was carried out in a mix containing $1.0 \mu \mathrm{g}$ of DNA, $0.2 \mathrm{mM}$ of deoxyribonucleoside-5' -triphosphate (dNTPs) mix, $10 \mu \mathrm{l}$ of $10 \mathrm{X}$ PCR reaction buffer, $1.25 \mathrm{mM} \mathrm{MgCl}_{2}, 1 \mu \mathrm{M}$ of HTLV-1-specific primers and 2.5 U of Taq DNA Polymerase (Perkin-Elmer, Cetus Co.) in a total volume of $50 \mu \mathrm{L}$. HTLV-1 primers to amplify LTR (737 bp), Pol (189 bp), Tax (159 bp) and a fragment of $1033 \mathrm{bp}$ covering Pol and env proviral regions were used (Figure 1). PCR reactions were performed under the following standardized cycling conditions: once 5 minutes at $94^{\circ} \mathrm{C}$ followed by 35 cycles of denaturation at $94^{\circ} \mathrm{C}$ for 2 minutes, 1 minute of annealing to $10^{\circ} \mathrm{C}$ under the calculated $\mathrm{Tm}$ of each pair of primers calculated (26), extension at $72^{\circ} \mathrm{C}$ for 2 minutes; and a final extension step at $72{ }^{\circ} \mathrm{C}$ for 10 minutes to complete the PCR. DNA of cell line MT2/HTLV $-1^{+}$was used as internal control for all PCR reactions. Detection and identification of DNA amplified fragments was performed by southern hybridization using appropriated ${ }^{[32]-} \mathrm{P}$-labeled oligonucleotides as probes

\section{RT-PCR procedures}

Poly $\mathrm{A}^{+}$RNA from approximately $2 \times 10^{5}$ primary cultured of oral epithelial cells/ml of HTLV-1 positive individuals as well as negative controls was extracted using the Dynabeads mRNA DIRECT ${ }^{\mathrm{TM}}$ kit (Dynal Biotech ASA, Oslo. Norway) following up the instructions of manufacturers. The Poly $\mathrm{A}^{+}$ RNA was used to detect by RT-PCR the mRNA of tax and pol. The cDNA synthesis was carried out in $10 \mathrm{mM}$ Tris- $\mathrm{HCl}(\mathrm{pH}$ 8.9), $90 \mathrm{mM} \mathrm{KCl}$ (1 X RT buffer), $0.9 \mathrm{mM} \mathrm{MnCl}, 375 \mu \mathrm{M}$ of each dNTP, and $750 \mathrm{nM}$ of primer for HTLV-1 pol SK111(-) and tax SK44(-), $100 \mathrm{ng}$ of poly $\mathrm{A}^{+} \mathrm{RNA}$ and $4 \mathrm{U}$ of Tth DNA polymerase (Thermus thermopilus DNA polymerase, Boerhinger Mannheim. Germany). The reactions were performed at $70^{\circ} \mathrm{C}$ for 30 minutes. After that, 40 cycles of a direct PCR was carried out in $10 \mathrm{mM}$ Tris- $\mathrm{HCl}$ (pH 8.9), 100 $\mathrm{mM} \mathrm{KCl,} \mathrm{(1} \mathrm{X} \mathrm{PCR} \mathrm{buffer),} 1.25 \mathrm{mM} \mathrm{MgCl} 2,0.75 \mathrm{mM}$ EDTA, 


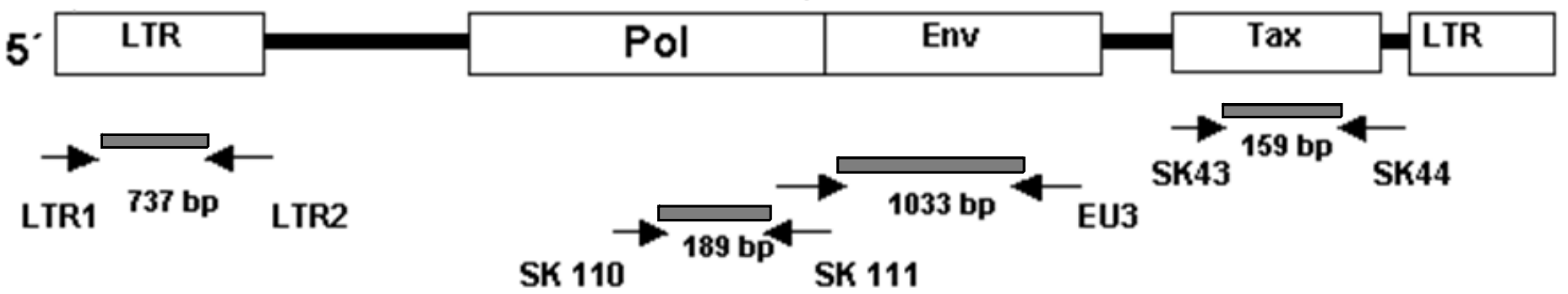

Figure 1. Schematic localization along the HTLV-1 proviral genome of several oligonucleotide primers pairs that were used to amplify HTLV-1 proviral sequences from DNA extracted of infected oral keratinocytes. Direction of arrows show the sense of each one of HTLV-1 oligonucleotide primers. Supplementary information about the primers is described in material and methods.

750 nM HTLV-1 primers SK110(+) and SK43(+). The annealing and extension conditions were the same of that previously described for direct PCR. The amplified products were visualized by fluorescence of DNA amplicons with ethidium bromide in agarose gel electrophoresis; the respective HTLV-1 amplified cDNA was identified by southern blot hybridization using appropriated ${ }^{[32]-} \mathrm{P}$-labeled oligonucleotides as probes (34).

\section{Statistical calculations}

A Fisher exact test was applied to calculate statistical differences between HAM/TSP and HC for sex, age, proviral region, RNA transcription and immunoglobulin class in plasma and $\mathrm{OF}$.

\section{RESULTS}

\section{Reactivity of OF and plasma to viral antigens}

The OD ratios in OF for HTLV-1 antibodies were significantly higher in HAM/TSP patients than in AC $(\mathrm{p}<0.01)$. No HTLV-1-specific antibodies were detected in OF and plasma from HTLV-1 seronegative controls. The $71.43 \%$ (10/14) of HAM/TSP patients had detectable levels of HTLV-1 specific $\operatorname{sIgA}$ in $\mathrm{OF}$ in comparison with $18.2 \%$ of the $\mathrm{AC}$ $(\mathrm{P}<0.01)$ (Table 1). Moreover in OF HTLV-1 specific IgG was detected in $100 \%(14 / 14)$ of HAM/TSP patients versus $72.7 \%$ $(8 / 11)$ of $\mathrm{AC}(\mathrm{P}<0.05)$. No significant differences between HAM/TSP and AC immunoglobulin class and sex and/or age were calculated.

Table 1. Reactivity of plasma and OF to HTLV-1 antigens as recorded by the ELISA Murex HTLV I + II (Murex Biotech Limited. Dartford. UK) diagnostic kit.

\begin{tabular}{|c|c|c|c|c|c|c|c|}
\hline \multirow[t]{2}{*}{ Health Status } & \multicolumn{3}{|c|}{ Plasma } & \multicolumn{3}{|c|}{ Oral Fluids } & \\
\hline & $\mathrm{IgG}$ & $\operatorname{IgM}$ & sIgA & $\mathrm{IgG}$ & $\operatorname{IgM}$ & sIgA & sIgA-Anti-Tax \\
\hline HAM/TSP & $14 / 14$ & $11 / 14$ & $0 / 14$ & $14 / 14$ & $11 / 14$ & $10 / 14$ & $8 / 14$ \\
\hline $\mathrm{AC}^{(\mathrm{a})}$ & $8 / 11$ & $2 / 11$ & $0 / 11$ & $8 / 11$ & $2 / 11$ & $3 / 11$ & $1 / 11$ \\
\hline $\mathrm{P}^{(\mathrm{b})}$ & $0.07^{\mathrm{NS}}$ & 0.004 & $1.00^{\mathrm{NS}}$ & $0.07^{\mathrm{NS}}$ & 0.004 & 0.04 & 0.03 \\
\hline
\end{tabular}




\section{Repertoire of HTLV-1 immunoglobulin class in OF}

As shown in figures $2 \mathrm{a}$ and $\mathrm{b}, \mathrm{IgG}$ antibodies to $\mathrm{p} 53-55$, p19 and r-tax were more frequents in OF from HAM/TSP, in contrast with anti-p28 and p24 which were more commonly registered in AC. Overall specific HTLV-1 $\operatorname{sIgA}$ for viral proteins was more frequently detected in OF of HAM/TSP (Figure $2 \mathrm{a}$ and $\mathrm{b}$ ). Furthermore there were significant differences in sIgA between HAM/TSP and AC for p40-Tax $(\mathrm{P}<0.05), \mathrm{p} 24(\mathrm{P}<0.05), \mathrm{p} 19 \quad(\mathrm{P}<0.001)$ and $\mathrm{r}-\mathrm{tax} \quad(\mathrm{P}<0.05)$ proteins (Figure 2c).
(A)

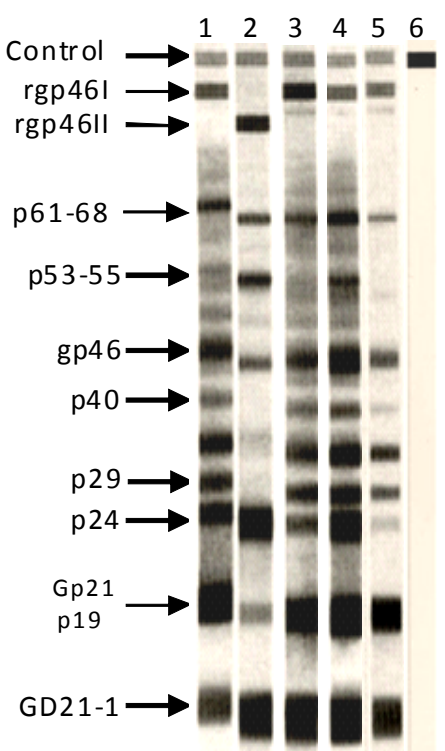

(B)

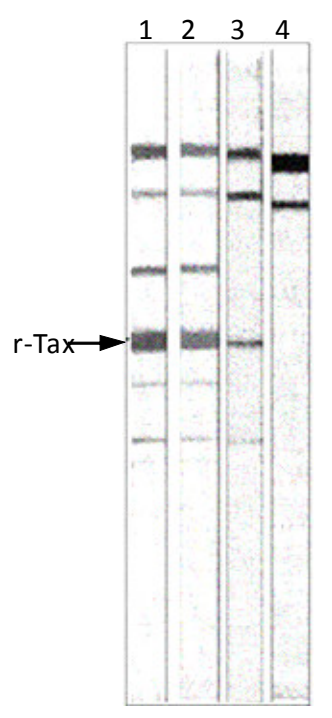

(C)

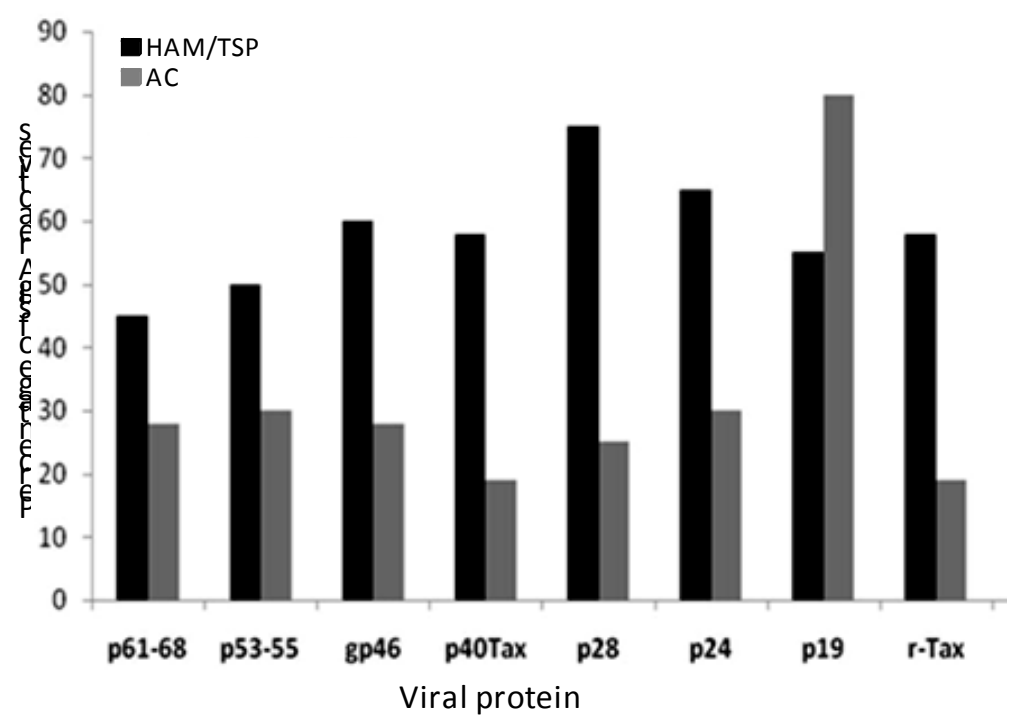

Figure 2. Reactivity detected by western blot in plasma and OF against HTLV-1 proteins of one HAM/TSP patient from southwest Colombia. (A). Western blot using the commercial HTLV blot 2.4 assay kit (Genelabs ${ }^{\circledR}$ Diagnostics Pte Ltd. Singapore Science Park. Singapore). (1) plasma control for HTLV-1 included with the kit; (2) plasma control for HTLV-2 included with the kit (3) Anti-IgG HTLV-1 in plasma; (4) Anti-IgG HTLV-1 in OF; (5) Anti-sIgA in OF; (6) Negative plasma control. (B). Western blot with a Tax recombinant protein of a HAM/TSP patient. (1) anti-r-tax -IgG in plasma. (2) anti-r-tax -IgG in OF. (3) anti-r-taxsIgA in OF (4) Negative OF control. (C). Frequencies of sIgA HTLV-1 specific class reactivity of HAM/TSP patients and AC OF from southwest Colombia against the different HTLV-1 proteins detected by western blot. (HAM/TSP). Tropical Spastic Paraparesis/HTLV-1-Associated Myelopathy. (AC). Asymptomatic Carrier.

\section{Immunophenotyping of oral epithelium cells cultured}

As shown in Figure 3 the double labeling CD3/CD4, CD8/CD19 did not show T4, T8 and B lymphocyte positive populations in oral epithelium primary cultures. Additionally the double staining CD14/CD45 also revealed no macrophages and monocytic cells contamination. The immune staining using a polyclonal anti-keratin antibody revealed that oral cells cultures have surface keratins revealing their epithelial origin. Not only by its morphology but also for the absence of CD4, the Langerhan cell contamination was excluded. In summary 
the primary cells from the oral epithelium had the phenotype $\left(\mathrm{CD}^{-} / \mathrm{CD} 8^{-} / \mathrm{CD} 14^{-} / \mathrm{CD} 52^{-} / \mathrm{A}-575-\beta-\right.$ keratin $\left.^{+}\right)$and were classified as keratinocytes. Furthermore the FACS results did not change in five days primary cultures in comparison with the same at 24 hours after seeding.

\section{Ex vivo detection of HTLV-1 proviral sequences.}

Figure 4 displays the southern blot results obtained from PCR assays performed in oral keratinocytes DNA by using different sets of HTLV-1 primers; in general the results indicated that HTLV-1 positive samples amplified overall at least one HTLV-1 proviral region integrated in the genome of oral keratinocytes (Table 2). Only $21.4 \%$ of proviral DNA of
HAM/TSP patients and $27.3 \%$ of AC exhibited amplification with all pairs of HTLV-1 primers tested in the study.

\section{Transcription of viral poly $\mathrm{A}^{+}$RNA.}

HTLV-1 seropositive individuals who had detectable levels of sIgA in their OF showed an active transcription of tax and pol mRNA. $57.1 \%(8 / 14)$ of HAM/TSP patients amplified by RTPCR both mRNA and only $27.3 \%$ (3/11) of AC (Figure 5a and b). Three AC which expressed viral mRNA corresponded to those that were $\operatorname{IgG}$ negatives in plasma but with detectable levels of sIgA in OF. In addition of these results, all HAM/TSP patients included in this study had detectable $\operatorname{IgG}$ and $\operatorname{sIgA}$ levels of an anti-50kDa recombinant tax protein.
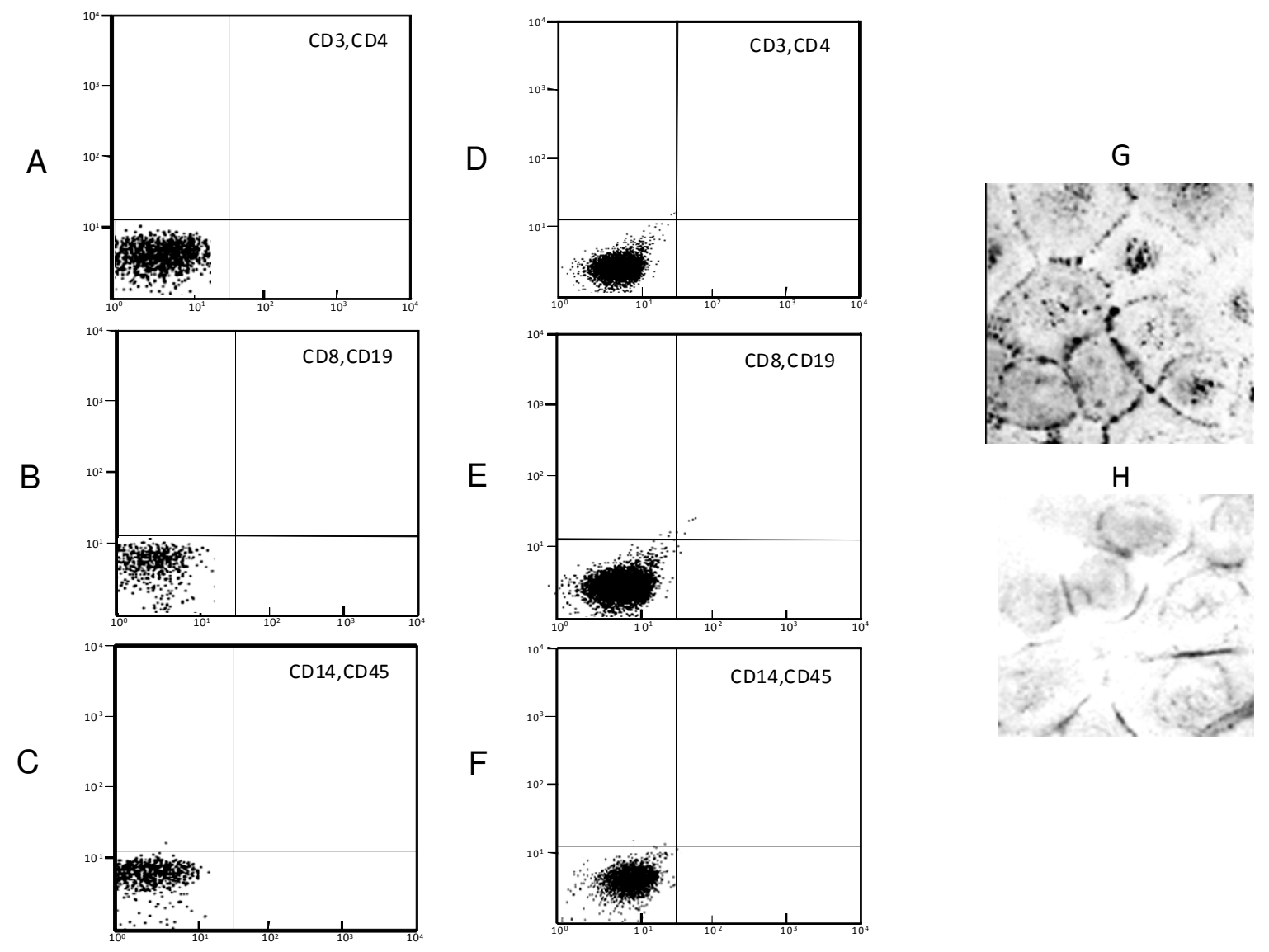

Figure 3. Two color flow citometry analyses of pairs of CD antigens as cell membranes markers in primary cultures from oral mucosa cells and keratin detection with the polyclonal antiserum A-575 (Daco, Carpinteria, CA) using the Vectastain Elite ABC kit (Vector, Burlingame. CA) kit. (A to C). FACS analyses in oral mucosa cells after 24 hours of cultured. (D to F). FACS results in oral mucosa cells after five days of cultured. (G) Immune staining of oral mucosa cells cultures after five days with the polyclonal antiserum A-575 (40X). (H). Negative Control IgG (40X). 


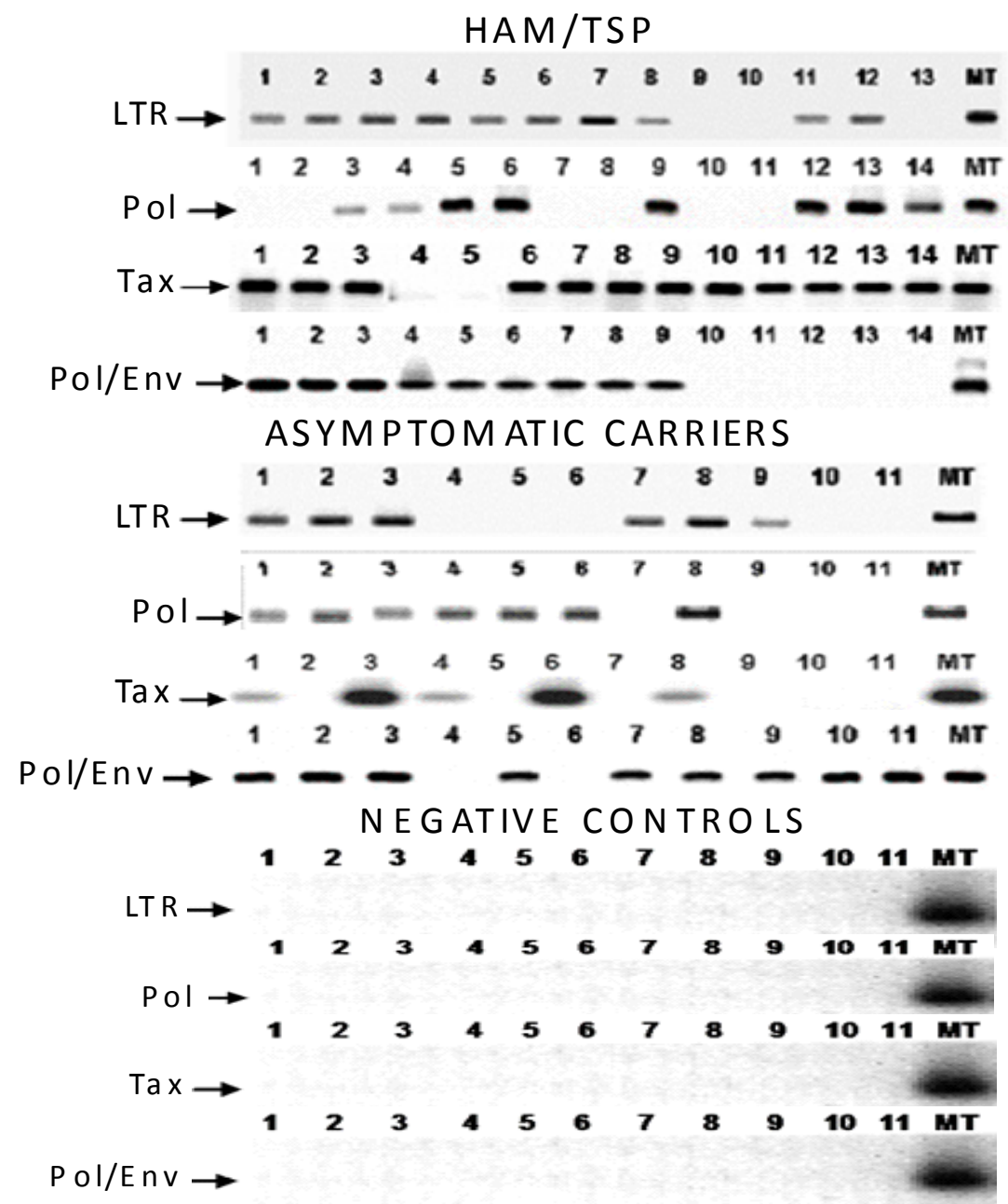

Figure 4. Southern blot hybridization of PCR products obtained from DNA of five days old primary oral keratinocytes from HAM/TSP and AC using different pairs of HTLV-1 oligonucleotide primers. LTR (737bp); Pol (189 bp); Pol-Env (1033 bp); Tax (159 bp). (MT) DNA from MT2 cell line with HTLV-1 provirus. Appropriated ${ }^{[32]-P-l a b e l e d ~ o l i g o n u c l e o t i d e s ~ w e r e ~ u s e d ~ a s ~ p r o b e s . ~}$

Table 2. Frequencies of HTLV-1 proviral regions amplified by PCR from DNA of oral keratinocytes from patients with HAM/TSP and asymptomatic carriers (AC)

\begin{tabular}{lcccc}
\hline Proviral region & Length (bp) $^{(\mathrm{a})}$ & HAM/TSP & AC & $\mathbf{P}^{(\mathrm{b})}$ \\
\hline LTR & 737 & $10 / 14$ & $6 / 11$ & $0.43^{\mathrm{NS}}$ \\
Pol & 189 & $11 / 14$ & $7 / 11$ & $0.65^{\mathrm{NS}}$ \\
Tax & 159 & $9 / 14$ & $5 / 11$ & $0.43^{\mathrm{NS}}$ \\
Pol-Env & 1033 & $9 / 14$ & $9 / 11$ & $0.41^{\mathrm{NS}}$ \\
\hline
\end{tabular}

(a). (bp) base pair. (b). P values calculated with a two tails Fisher exact test. (NS), no statistically significant differences. 
$\operatorname{Tax}$

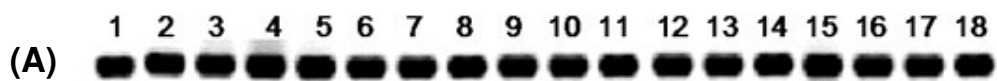

Pol

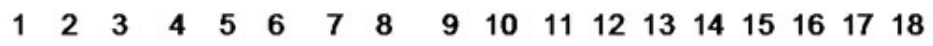

(B)

\section{Beta actin}

(C)

Figure 5. Southern blot hybridization from RT-PCR products of (A) Tax and (B) Pol polyA ${ }^{+}$RNA obtained from oral epithelial cells of those HAM/TSP patients and Healthy Carriers. who had detectable levels of sIgA in their oral fluids. (C) An internal $\beta$ actin gene reporter $159 \mathrm{bp}$ fragment was included as a control for transcription of cellular genes. Appropriated ${ }^{[32]-} \mathrm{P}-\mathrm{labeled}$ oligonucleotides were used as probes. (1 a 12), RT-PCR products of polyA+ RNA extracted from HAM/TSP patients; (13 a 15), RT-PCR products of RNA from asymptomatic carriers (AC); (16) RT-PCR of Poly A+ RNA from Peripheral Blood Mononuclear Cell (PBMC) of a HAM/TSP patient; (17). RT-PCR of poliA+ RNA from from MT2 cell line with HTLV-1 provirus. (18) PCR of MT2 DNA cell line with HTLV-1 provirus.

\section{DISCUSSION}

In the present study we obtained strong evidence to support the existence of a closed association between detectable levels of HTLV-1 specific sIgA in OF and the integration of viral cDNA sequences which promote an active transcription of poly A+ RNA of tax and pol genes in oral keratinocytes. We also demonstrate that HTLV-1 infection in oral cavity is not restricted to the epithelium of HAM/TSP patients, as well as to the asymptomatic carriers; however difference between sIgA levels in OF and expression of tax and pol genes between HAM/TSP patients and AC were observed.

The HTLV-1 integration into DNA of oral keratinocytes which is reported in this work spans the spectra of cell targets for HTLV-1 infection. We previously reported the existence of an association of the presence, in HAM/TSP patients, of free genomic HTLV-1 RNAs with an active production of $\operatorname{sIgA}$ in OF (33). The differences recorded between HAM/TSP and AC in the mucosal associated response suggested that not only immunological but cellular changes occur during progression to disease. In general, our results not only supported others previously published but showed that oral keratinocytes are effective cell targets during the systemic spreading of HTLV-1 infection in mucosa $(5,6)$.

The immune status of those HAM/TSP subjects included in this study, having anti-HTLV-1 IgG and sIgA in OF as well as free viral RNA templates in oral fluids (33), suggest that the infection of HTLV-1 to epithelial targets could occur possibly by contact cell-to-cell with HTLV-1 infected salivary lymphocytes. However still remain to be explain whether those lymphocytes circulate for longer in saliva or they are newly deposit in mouth saliva by extravassing from microcirculation as was previously reported $(2,38)$. An indirect evidence to explain the infection of oral keratinocytes by cell-to-cell contact between $\mathrm{T}$ cells and oral keratinocytes, is that HTLV-1 is primarily transmitted either by breast-feeding $(4,7)$. 
Although the complex receptor for HTLV-1 entry to lymphocytes is partially documented, in other non lymphocytic cells targets, as keratinocytes, the mechanism of infection is still matter of investigation $(25,13)$. Several data suggest the ubiquitous glucose transporter GLUT1 act as receptor for Deltaretroviruses HTLV-1 and HTLV-2 envelopes (Env), mediating viral binding and entry (35). GLUT-1 specifically binds a soluble form of both the HTLV-1 and HTLV-1I SU proteins in $\mathrm{T}$ cell and non- $\mathrm{T}$ cell lines, and was shown to be critical for efficient entry of HTLV-1I-pseudotyped virions (13). The role of GLUT-1 as viral co-receptor for HTLV-1 interaction with target cell and efficient virus spreading correlated largely with heparan sulfate proteoglycan (HSPG) expression on target cells in activated CD4+ $\mathrm{T}$ cells and cord blood lymphocytes susceptible to HTLV-1 infection. Altogether these results indicate that GLUT1 and HSPGs are important for an efficient HTLV-1 cell-to-cell transmission but raise concerns on the role of GLUT1 as the HTLV-1 primary binding receptor in lymphocytes (13).

In order to explain the effective integration of HTLV-1 genome in oral keratinocytes, we could argue that a similar complex cell receptor would be important in cell to cell infection. Previous results showed a weak expression of GLUT 1 in epithelial cells of the normal mucosa $(35,8)$; however increasing of GLUT-1 as receptor in this kind of cells could be enhanced by an altered physiological status such as a virus infection. To support this statement, previous data about GLUT -1 localization of expression in the epithelial layers of oral mucosa equivalents, that were grown in a defined plasma-free culture medium without a feeder layer, showed that GLUT-1 was expressed in both basal cell layer and suprabasal cell layer of oral mucosa epithelium (8). Although the evidences could support the hypothesis that GLUT-1 and HSPG would be important molecules playing a role in interaction between HTLV-1 SU proteins and cell target membrane in keratinocytes, it is still matter of discussion.

From the PCR data obtained in this study it was possible to observe that some HAM/TSP and AC keratinocytes DNA did not amplify more than one pair of HTLV-1 specific primers. Although some failure during the PCR process could be responsible for a remote possible mistaken interpretation of results; however another real explanation is that defective proviruses would be generated during the infection process to oral keratinocytes. In order to support the last explanation, previous studies report the existence of defective HTLV-1 provirus in lymphocytic infections not only in $\operatorname{ATL}(9,20,11$, 15) but also in HAM/TSP patients $(29,30,16,14)$. In this sense our results would be the first to document the existence of defective HTLV-1 provirus in infected oral keratinocytes. Although not direct evidence have obtained, the presence of defective provirus not only in lymphocytes but in oral keratinocytes, strongly suggest the possibility that low levels of viremia and/or low efficiency in the contact cell-to-cell could possibly favor post integration process that increase the frequency of defective provirus (15); however this statement in oral mucosa keratinocytes needs to be tested.

Although our results indirectly evidence an active infection in oral mucosa which was correlated with an active immune process of mucosa via specific anti-Tax HTLV-1 $\operatorname{sIg} \mathrm{A}$, still remains the question weather OF and saliva are really infective fluids. In these sense, inoculation of saliva cells and cell-free saliva from healthy carriers and patients with HAM/TSP into WKA and F344 female rats produced a successful infection (32). By nested PCR from inoculated rat DNA HTLV-1 proviruses in PBMC, spleen, thymus, salivary glands, spinal cord, kidney and brain were detected (32).

In general the results obtained in this study in conjunction with others previously reported, would support the hypothesis that HTLV-1 could primarily exists in oral secretions or it can reach the saliva through the blood after minimal bruises in the oral cavity and potentially could infect cells of the oral epithelium. However, the characteristics of such infection and their effects on the mucosal immune response still remain not fully understood.

\section{ACKNOWLEDGMENTS}

We thanks to all patients who participated of the study as 
donors of blood and oral fluid samples. Our special thanks to the nursing personal of Tumaco, Buenaventura and Cali Hospitals for the important help in the management of clinical records. This work was support in convention with Colciencias, Colombia and Universidad del Valle, Cali, Colombia (project number1106-04-199-96), and with Universidad del Valle financial funds under the contract number 1576-2008.

\section{REFERENCES}

1. Achiron, A.; Higuchi, I.; Takenouchi, N.; Matsuok, E.; Hashimoto, K.; Izumo, S.; Shohat, B.; Osame, M. (1997). Detection of HTLV type I provirus by in situ polymerase chain reaction in mouthwash mononuclear cells of HAM/TSP patients and HTLV type I carriers. AIDS Res. Hum. Retrovirus. 13,1067-1070.

2. Balestrieri, E.; Ascolani, A.; Igarashi, Y.; Oki, T.; Mastino, A.; Balzarini, J.; Macchi, B. (2008). Inhibition of cell-to-cell transmission of human Tcell lymphotropic virus type 1 in vitro by carbohydrate-binding agents. Antimicrob. Agents Chemother.52(8), 2771-2779.

3. Bradford, M. (1976). A rapid and sensitive method for the quantitation of microgram quantities of protein utilizing the principle of protein-dye binding. Anal. Biochem. 72, 248-254.

4. Carles, G.; Tortevoye, P.; Tuppin, P.; Ureta-Vidal, A.; Peneau, C.; El Guindi, W.; Gessain, A. HTLV1 infection and pregnancy. J Gynecol Obstet Biol Reprod (Paris). 2004;33:14-20.

5. Franchini, G.; Mann, D.L.; Popovic, M.; Zicht, R.R.; Gallo, R.C.; WongStaal, F. (1985). HTLV-1 infection of T and B cells of a patient with adult T-cell leukemia-lymphoma (ATLL) and transmission of HTLV-1 from B cells to normal T cells._Leuk. Res. 9(11), 1305-1314.

6. Giozza, S.P.; Santos, S.B.; Martinelli, M.; Porto, M.A.; Muniz, A.L.; Carvalho, E.M. (2008). Salivary and lacrymal gland disorders and HTLV-1 infection._Rev. Stomatol. Chir. Maxillofac. 109(3), 153-157.

7. Igakura, T.J.C.; Stinchcombe, P.K.; Goon, G.P.; Taylor, J.N.; Weber, G.M.; Griffiths, Y.; Tanaka, M.; Osame, M.; Bangham, C.R.(2003). Spread of HTLV-1 between lymphocytes by virus-induced polarization of the cytoskeleton. Science. 299, 1713-1716.

8. Jin. Q.; Agrawal. L.; Vanhorn-Ali, Z.; Alkhatib, G. (2006). GLUT-1independent infection of the glioblastoma/astroglioma U87 cells by the human T cell leukemia virus type 1._Virology.353 (1), 99-110.

9. Kamihira, S.; Sugahara, K.; Tsuruda, K.; Minami, S.; Uemura, A.; Akamatsu, N.; Nagai, H.; Murata, K.; Hasegawa, H.; Hirakata, Y.; Takasaki, Y.; Tsukasaki, K.; Yamada, Y. (2005). Proviral status of HTLV-1 integrated into the host genomic DNA of adult T-cell leukemia cells. Clin. Lab. Haematol. 27(4), 235-41.

10. Kaplan, J.E.; Khabbaz, R.F.; Murphy, E.L.; Hermansen, S.; Roberts, C.; Lal, R.; Heneine, W.; Wright, D.; Matijas, L.; Thomson, R. (1996). Male- to-female transmission of human T-cell lymphotropic virus types I and II: association with viral load. The Retrovirus Epidemiology Donor Study Group. J. Acquir. Immune Defic. Syndr. Hum. Retrovirol. 12, 193-201.

11. Korber, B.; Okayama, A.; Donnelly, R.; Tachibana, N.: Essex M. (1991). Polymerase chain reaction analysis of defective human T-cell leukemia virus type I proviral genomes in leukemic cell of patients with adult Tcell leukemia. J. Virol. 65, 5471-5475.

12. Li, H.C.; Biggar, R.J.; Miley, W.J.; Maloney, E.M.; Cranston, B.; Hanchard, B.; Hisada, M. (2004). Provirus load in breast milk and risk of mother-to-child transmission of human T Lymphotropic virus type I. $J$. Infect. Dis. 190, 1275-1278.

13. Manel, N. Kim, F.J.; Kinet, S.; Taylor, N.; Sitbon, M.; Battini J. L. (2003). The ubiquitous glucose transporter GLUT-1 is a receptor for HTLV. Cell. 115, 449.

14. Mangano, A.M.; Remesar, M.; del Pozo, A.; Sen L. (2004). Human T Lymphotropic virus types I and II proviral sequences in Argentinean blood donors with indeterminate western blot patterns._J. Med. Virol.74, 323-327.

15. Miyazaki, M.; Yasunaga, J.; Taniguchi, Y.; Tamiya, S.; Nakahata, T.; Matsuoka, M. (2007). Preferential selection of human T-cell leukemia virus type 1 provirus lacking the $5^{\prime}$ long terminal repeat during oncogenesis. J. Virol. 81(11), 5714-23.

16. Morozov, V.A.; Ellerbrok, H.; Fleischer, C.; Brackmann, H.H.; Pauli G. (2002). Defective human T-cell leukaemia virus type 1 (HTLV-1) genomes: no evidence in serologically indeterminate German blood donors but new type detected in established cell lines._J. Med. Virol. 66, 102-106.

17. Murphy, E.L; Blattner, W.A. (1988). HTLV-1-associated leukemia: a model for chronic retroviral diseases. Ann. Neurol. 23, S174-S180.

18. Offen, D.; Achiron, A.; Wasserman, L.; Miller, M.; Shakai, M.; Dabby, R.; Gorodin, S.; Shohat B. (1998). HTLV-1 in mouthwash cells from HAM/TSP patient and asymptomatic carriers. Arch. Virol.143, 10291034.

19. Ohshima, K. (2007). Pathological features of diseases associated with human T-cell leukemia virus type I. Cancer Sci. 98(6), 72-78.

20. Oshima, K.; Kikuchi, M.; Masuda, Y.; Kobari. S.; Sumiyoshi, Y.; Eguchi, F.; Mohtai, H.; Yoshida, T.; Takeshita, M.; Kimura N. (1991). Defective provirus form of human T-cell leukemia virus type I in adult Tcell leukemia/lymphoma: clinopatological features. Cancer Res. 51, 4639-4644.

21. Okayama, A.; Chen, Y.; Tachibana, N.; Shiori, S.; Lee, T.H.; Tsuda, K.; Essex M. (1991). High incidence of antibodies to HTLV-1-tax in blood relatives of adult T cell leukemia patients. J. Infect. Dis. 163, 47-52.

22. Okochi, K.; Sato, H.; Hinuma, Y. (1984). A retrospective study on transmission of adult $\mathrm{T}$ cell leukemia virus by blood transfusion: seroconversion in recipients. Vox Sang. 46,245-253.

23. Osame, M.; Matsumoto, M.; Usuku, K.; Izumo, S.; Ijichi. N.; Amitami, H.; Tara, M.; Igata, A. (1987). Chronic progressive myelopathy associated with elevated antibodies to Human T-Lymphotropic virus type 
1 and adult T-cell leukemilike cells. Ann. Neurol.21, 117-122.

24. Osame, M.; Usuku, K.; Izumo, S.; Ijichi, N.; Amitami, H.; Igata, A.; Matsumoto, M.;Tara M. (1986). HTLV-1 associated myelopathy, a new clinical entity. Lancet, 1, 1031-1032.

25. Overbaugh, J.; Miller, A.D.; Eiden, M.V. (2001). Receptors and entry cofactors for retroviruses include single and multiple transmembranespanning proteins as well as newly described glycophosphatidylinositolanchored and secreted proteins._Microbiol. Mol. Biol. Rev.65, 371-389.

26. Perandin, F.; Cariani, A.; Bonfanti, C.; Trainini, L.; Magoni, M., Manca, N. (2006). Human T-cell lymphotropic virus type I (HTLV-1) confirmed by PCR-Southern blot and sequencing analysis in a woman with tropical spastic paraparesis._Neurol. Sci. 27(4), 257-60.

27. Poiesz, B.J.; Ruscetti, F.W.; Gazdar. A.F.; Bunn, P.A.; Minna, J.D.;Gallo RC.(1980): Detection and isolation of type C retrovirus particles from fresh and cultured lymphocytes of a patient with cutaneous T-cell lymphoma. Proc. Natl. Acad. Sci. USA. 77, 7415-7419.

28. Proietti, F.A.; Carneiro-Proietti, A.B.; Catalani-Soares, B.C.; Murphy, E.L. (2005). Global epidemiology of HTLV-1 infection and associated diseases. Oncogene. 24, 6058-68.

29. Ramirez, E.; Cartier, L.; Rios, M.; Fernandez, J. (1998). Defective human T-cell lymphotropic virus type I (HTLV-1) provirus in 10 Chilean seronegative patients with tropical spastic paraparesis or HTLV-1associated myelopathy. J. Clin. Microbiol.36, 1811-1813.

30. Ramirez, E.; Fernandez, J.; Cartier, L.; Villota, C.; Rios, M. (2003). Defective human T-cell lymphotropic virus type I (HTLV-1) provirus in seronegative tropical spastic paraparesis/HTLV-1-associated myelopathy (HAM/TSP) patients. Virus Res. 91,231-239.

31. Ramirez-Solis, R.; Rivera-Perez, J.; Wallace, J.D.; Wims, M.; Zheng, H.; Bradley, A. (1992). Genomic DNA microextraction: A method to screen numerous samples. Anal. Biochem. 201, 331-335.

32. Shohat, M.; Shohat, B.; Achiron, A. (2006). Human T-lymphotropic virus type-1 (HTLV-1) in Israeli patients and their family relatives and its transmission to rats._Med Microbiol Immunol.195(2), 93-9.

33. Soto-Ramirez, L.E.; Garcia-Vallejo, F.; Renjifo, B.; Vergara, A.; Borrero, I.: Marlink, R.; Essex, M. (1995). Human T-Lymphotropic virus type 1 (HTLV-1)-specific antibodies and cell-free RNA in crevicular fluid rich saliva from patients with tropical spastic paraparesis/HTLV-1associated myelopathy. Viral Immunol.8, 141-150.

34. Southern, E.M. (1975). Detection of specific sequences among DNA fragments separated by gel electrophoresis. J. Mol. Biol. 98,503-517.

35. Takenouchi, N.; Jones, K.S.; Lisinski, I.; Fugo, K.; Yao, K.; Cushman, S.W.; Ruscetti, F.W.; Jacobson, S. (2007). GLUT1 is not the primary binding receptor but is associated with cell-to-cell transmission of human T-cell leukemia virus type 1. J. Virol. 81(3), 1506-1510.

36. Ureta-Vidal, A.; Angelin-Duclos, C.; Tortevoye, P.; Murphy, E.; Lepère, J.F.; Buigues, R.P.; Jolly, N.; Joubert, M.; Carles, G.; Pouliquen, J.F.; de Thé, G.; Moreau, J.P.; Gessain, A. (1999) Mother-to-child transmission of human T-cell-leukemia/lymphoma virus type I: implication of high antiviral antibody titer and high proviral load in carrier mothers._Int. J. Cancer.82(6), 832-6.

37. Verdonck, K.; González, E.; Van Dooren, S.; Vandamme, A.M.; Vanham, G.; Gotuzzo, E. (2007). Human T-Lymphotropic virus 1: recent knowledge about an ancient infection. Lancet. 7(4), 266-281.

38. Yamamoto, T.; Terada, K.; Nishida, N.; Moriuchi, R.; Shirabe, S.; Nakamura, T.; Tsuji, Y.; Miyamoto, T.; Katamine, S. (1995). Inhibitory activity in saliva of cell-to-cell transmission of human T-cell Lymphotropic virus type 1 in vitro: evaluation of saliva as an alternative source of transmission._J. Clin. Microbiol.33(6),1510-1515. 